\title{
Regulation of boar sperm functionality by the nitric oxide synthase/nitric oxide system
}

\author{
Florentin-Daniel Staicu ${ }^{1,2} \cdot$ Rebeca Lopez-Úbeda ${ }^{2,3}$ • Jon Romero-Aguirregomezcorta ${ }^{1,2,4}$ • \\ Juan Carlos Martínez-Soto ${ }^{2,5} \cdot$ Carmen Matás Parra ${ }^{1,2}$
}

Received: 24 April 2019 / Accepted: 8 July 2019 / Published online: 19 July 2019

(C) The Author(s) 2019

\begin{abstract}
Purpose Nitric oxide (NO) is a free radical synthesized mainly by nitric oxide synthases (NOSs). NO regulates many aspects in sperm physiology in different species. However, in vitro studies investigating NOS distribution, and how NO influences sperm capacitation and fertilization (IVF) in porcine, have been lacking. Therefore, our study aimed to clarify these aspects.

Methods Two main experiments were conducted: (i) boar spermatozoa were capacitated in the presence/absence of Snitrosoglutathione (GSNO), a NO donor, and two NOS inhibitors, $\mathrm{N}^{\mathrm{G}}$-nitro-L-arginine methyl ester hydrochloride (L-NAME) and aminoguanidine hemisulfate salt (AG), and (ii) IVF was performed in the presence or not of these supplements, but neither the oocytes nor the sperm were previously incubated in the supplemented media.

Results Our results suggest that NOS distribution could be connected to pathways which lead to capacitation. Treatments showed significant differences after $30 \mathrm{~min}$ of incubation, compared to time zero in almost all motility parameters $(P<0.05)$. When NOSs were inhibited, three protein kinase $\mathrm{A}$ (PKA) substrates $(\sim 75, \sim 55$, and $\sim 50 \mathrm{kDa})$ showed lower phosphorylation levels between treatments $(P<0.05)$. No differences were observed in total tyrosine phosphorylation levels evaluated by Western blotting nor in situ. The percentage of acrosome-reacted sperm and phosphatidylserine translocation was significantly lower with L-NAME. Both inhibitors reduced sperm intracellular calcium concentration and IVF parameters, but L-NAME impaired sperm ability to penetrate denuded oocytes.
\end{abstract}

Conclusions These findings point out to the importance of both sperm and cumulus-oocyte-derived NO in the IVF outcome in porcine.

Keywords Nitric oxide $\cdot$ Nitric oxide synthase $\cdot$ Spermatozoa $\cdot$ Capacitation $\cdot$ In vitro fertilization

\section{Introduction}

Electronic supplementary material The online version of this article (https://doi.org/10.1007/s10815-019-01526-6) contains supplementary material, which is available to authorized users.

\section{Carmen Matás Parra}

cmatas@um.es

1 Department of Physiology, Veterinary Faculty, University of Murcia, International Excellence Campus for Higher Education and Research (Campus Mare Nostrum), Murcia, Spain

2 Institute for Biomedical Research of Murcia (IMIB), Murcia, Spain

3 Department of Cell Biology and Histology, Faculty of Medicine, University of Murcia, International Excellence Campus for Higher Education and Research (Campus Mare Nostrum), Murcia, Spain

4 Department of Physiology, Faculty of Medicine and Nursing, University of the Basque Country (UPV/EHU), Bizkaia, Spain

5 IVI-RMA Global, Murcia, Spain
Several reactive oxygen species (ROS), including hydrogen peroxide, superoxide anion, and NO, have been shown to be involved in processes important for sperm physiology. Under normal, tightly regulated physiologic conditions, these ROS are essential for the sperm to acquire the fertilizing ability [1]. At physiologic levels, NO has been demonstrated to modulate sperm capacitation and acrosome reaction, and sperm motility, and it may also have an anti-apoptotic effect (reviewed by [2]). Besides, the importance of NO in oocyte maturation and subsequent fertilization has also been revealed [3].

It is known that sperm can produce $\mathrm{NO}$, but the evidence that the endogenous synthesis is sufficient to be physiologically significant is equivocal [4]. Various cell types in the mammalian female reproductive tract generate substantial levels of NO, which in turn determine the S-nitrosylation of sperm proteins. Thus, in vivo is more likely to occur as a response to the NO 
generated by the female tract cells, rather than by autocrine effects of sperm-generated NO. Furthermore, it has been demonstrated that activity of NOSs, the enzymes responsible for NO synthesis, can be modulated by sexual hormones [5]; therefore, the NO levels will vary during the estrus cycle [6] which in turn could regulate the fertilization process.

Sengoku et al. [7] showed that low concentrations of NO may have a physiologic role in fertilization by enhancing the capacitation and binding to the zona pellucida (ZP), but not by inducing the acrosome reaction or facilitating oocyte penetration. On the other hand, Herrero et al. [8] showed that the incubation of spermatozoa with NOS inhibitors reduced the IVF outcome in mouse. These authors observed that NOS inhibition during sperm capacitation impaired the spontaneous acrosome reaction, as well as the IVF. However, studies on the production of certain substances during the interaction of gametes that affect IVF performance have been scarce. In this sense, it has been described that both spermatozoa and cumulus cells produce $\mathrm{NO}$ and this molecule takes part in the fertilization process $[3,9]$. Nevertheless, despite all the studies carried out to determine the role of NO on sperm function, we should improve our understanding of how this gas modulates it by performing tests that bring us closer to the physiological conditions during fertilization. In relation to the studies using human spermatozoa and their interaction with the female gamete, it has only been possible to analyze hemizone binding assays [7, 10], logically for ethical reasons. On the other hand, IVF assays performed in mouse were done with epididymal spermatozoa which cannot be considered physiologically mature. Therefore, these studies, despite the important information they provide, cannot be considered conclusive.

It appears that while $\mathrm{NO}$ synthesis in sperm is required for IVF, the free radicals generated in the medium, including NO, could be in excess and be harmful, as seen in certain infertility cases [11]. In porcine, they could affect the functionality of both spermatozoa and oocytes and, somehow, contribute to the problem of polyspermy (i.e., fertilization of an ovum by more than one spermatozoon) in this species. However, polyspermy could be used as a tool to evaluate sperm functionality since a higher percentage of penetrated oocytes and sperm number per penetrated oocyte correlate with sperm quality [12].

For all the reasons above, this paper aims to determine the role of the NOS/NO system in the fertilizing capacity of boar spermatozoa. Besides, since the NO function during the fertilization process in porcine has not yet been determined, we hypothesized that by regulating the NOS/ NO system, the IVF efficiency could be improved. To develop this hypothesis, we determined, at first, the NO effects on the spermatozoon, followed by its impact on the IVF.

\section{Materials and methods}

\section{Ethics}

The study was carried out following the Spanish Policy for Animal Protection RD 53/2013, which meets European Union Directive 2010/63/UE on animal protection. The Ethics Committee of Animal Experimentation of the University of Murcia and the Animal Production Service of the Agriculture Department of the Region of Murcia (Spain) (ref. no. A13160609) approved the procedures performed in this work.

\section{Materials}

Unless otherwise stated, chemicals and reagents were purchased from Sigma-Aldrich Química S.A. (Madrid, Spain). Equine chorionic gonadotropin (eCG; Foligon) was supplied by Intervet International B.V. (Boxmeer, Holland), human chorionic gonadotropin (hCG; Veterin Corion) by Divasa-Farmavic (Barcelona, Spain), and Percoll by GE Healthcare (Uppsala, Sweden). The prolonged anti-fade mounting medium (SlowFade Antifade Kit) was obtained from Invitrogen (Paisley, $\mathrm{UK}$ ). $\mathrm{N}^{\mathrm{G}}$-nitro-L-arginine methyl ester (L-NAME; 483125) was purchased from Calbiochem (distributed by Merck Chemicals, Beeston, Nottingham, UK).

\section{Culture media}

In vitro maturation (IVM) of pig oocytes was carried out using the NCSU-37 medium [13] supplemented with $0.57 \mathrm{mM}$ cysteine, $1 \mathrm{mM}$ dibutyryl-cAMP, $5 \mathrm{mg} / \mathrm{mL}$ insulin, $50 \mu \mathrm{M} \beta$ mercaptoethanol, $10 \mathrm{IU} / \mathrm{mL}$ eCG, $10 \mathrm{IU} / \mathrm{mL}$ hCG, and $10 \%$ $v / v$ porcine follicular fluid.

Sperm capacitation and IVF were performed using Tyrode's albumin lactate pyruvate (TALP) medium [14], consisting of $114.06 \mathrm{mM} \mathrm{NaCl}, 3.2 \mathrm{mM} \mathrm{KCl}, 8 \mathrm{mM} \mathrm{Ca}$ lactate $5 \mathrm{H}_{2} \mathrm{O}, 0.5 \mathrm{mM} \mathrm{MgCl}{ }_{2} \cdot 6 \mathrm{H}_{2} \mathrm{O}, 0.35 \mathrm{mM} \mathrm{NaH}{ }_{2} \mathrm{PO}_{4}$, $25.07 \mathrm{mM} \mathrm{NaHCO}_{3}, 10 \mathrm{mM} \mathrm{Na}$ lactate, $1.1 \mathrm{mM} \mathrm{Na}$ pyruvate, $5 \mathrm{mM}$ glucose, $2 \mathrm{mM}$ caffeine, $3 \mathrm{mg} / \mathrm{mL}$ bovine serum albumin (BSA, A-9647), $1 \mathrm{mg} / \mathrm{mL}$ polyvinyl alcohol (PVA), and $0.17 \mathrm{mM}$ kanamycin sulfate.

\section{Sperm collection}

Sperm samples were collected from boars with proven fertility by the gloved hand method. Standard laboratory techniques were applied to evaluate sperm concentration, motility, acrosome integrity, and normal morphology. 


\section{Immunocytochemistry: NOS detection and Tyr-P by IIF}

To determine NOS localization, a method adapted from Meiser and Schulz [15] was used. Briefly, ejaculated boar sperm were washed with Dulbecco's phosphate-buffered saline without calcium chloride and magnesium chloride (DPBS) and spread on glass slides coated with poly L-lysine. Spermatozoa were airdried and fixed for $20 \mathrm{~min}$ in ice-cold $3 \% v / v$ paraformaldehyde in DPBS containing $120 \mathrm{mM}$ sucrose. They were gently rinsed with DPBS, incubated for $10 \mathrm{~min}$ in ice-cold $100 \% v / v$ methanol, and triply washed with DPBS. Specimens were treated with blocking I solution (10\% w/v BSA, $1 \% v / v$ Triton X-100, dissolved in distilled water, $1 \mathrm{~h}, 20^{\circ} \mathrm{C}$ ). Next, sperm were incubated with blocking II solution ( $2 \% w / v$ BSA, $1 \% v / v$ Triton $\mathrm{X}-100$, dissolved in distilled water, $1 \mathrm{~h}, 37^{\circ} \mathrm{C}$ ), which included the primary anti-NOS antibodies (all three produced in mouse, 1:1000): anti-nNOS (N2280, monoclonal, clone NOS-B1, obtained with a recombinant nNOS fragment [amino acids 1-181] from rat brain), anti-eNOS (N9532, monoclonal, clone NOSE1, obtained with a synthetic peptide corresponding to bovine eNOS [amino acids 1185-1205 with an N-terminally added lysine] conjugated to keyhole limpet hemocyanin [KLH]), or anti-iNOS (N9657, monoclonal, clone NOS-IN, obtained with a synthetic peptide corresponding to iNOS from mouse macrophage [amino acids 1126-1144] conjugated to KLH). These anti-NOS antibodies were chosen since their reactivity with porcine sperm extracts was previously shown by Aquila et al. [16]. Then, the specimens were triply washed with blocking II and probed overnight $\left(4^{\circ} \mathrm{C}\right)$ with a FITC-labeled secondary antibody (goat anti-mouse, 1:1000, diluted in blocking II). For controls, specimens were processed in the absence of primary and/or secondary antibody.

Tyrosine phosphorylation (Tyr-P) location was studied as previously described [17], using an anti-phosphotyrosine antibody (4G10, Millipore, CA, USA, 1:300 in 1\% w/v BSA). The secondary antibody was a fluorescein-conjugated goat anti-mouse (Bio-Rad Laboratories, Madrid, Spain, 1:400 in 1\% w/v BSA).

All images were taken at $\times 1000$ (for NOS distribution) and $\times 400$ (for Tyr-P location) magnifications, using the AxioVision Imaging System (Rel. 4.8) with an AxioCam HRc camera (Carl Zeiss, Göttingen, Germany) attached to a Leica DMR fluorescence microscope (Leica Microsystems, Wetzlar, Germany) equipped with a fluorescent optical blue filter (BP 480/40; emission BP 527/30).

\section{Spermatozoa motion assay}

To evaluate sperm motility, computer-assisted sperm analysis (CASA) was performed (ISAS ${ }^{\circ}$ system, PROiSER R+D S.L., Valencia, Spain), and the following parameters were studied: total motility (\%), progressive motility (\%), curvilinear velocity (VCL, $\mu \mathrm{m} / \mathrm{s})$, straight-line velocity (VSL, $\mu \mathrm{m} / \mathrm{s}$ ), average path velocity (VAP, $\mu \mathrm{m} / \mathrm{s}$ ), linearity of the curvilinear trajectory (LIN, ratio of VSL/VCL, \%), straightness (STR, ratio of VSL/VAP, \%), amplitude of lateral head displacement $(\mathrm{ALH}, \mu \mathrm{m})$, wobble of the curvilinear trajectory (WOB, ratio of VAP/VCL, \%), and beat cross-frequency (BCF, Hz). For this purpose, a $4-\mu \mathrm{L}$ drop of the sample was placed on a warmed $\left(38.5^{\circ} \mathrm{C}\right)$ Spermtrack ST20 chamber (PROISER R+ D S.L) and analyzed using a phase-contrast microscope $(\times 200$ magnification; Leica DMR, Wetzlar, Germany). The setting parameters were 60 frames at 30 frames/s, of which spermatozoa had to be present in at least 15 to be counted. Spermatozoa with a VCL less than $10 \mu \mathrm{m} / \mathrm{s}$ were considered immotile. A minimum of five fields per sample were evaluated, counting a minimum of 200 spermatozoa per field.

\section{Western blotting: PKAs-P and Tyr-P}

Sperm protein extracts were isolated from $1 \times 10^{6}$ spermatozoa/sample and immunoblotted as described by Navarrete et al. [18] with the following antibodies: antiphospho-PKA substrates (9624, Cell Signaling Technology, Beverly, USA, 1:2000), anti-phosphotyrosine (4G10, Millipore, CA, USA, 1:10000), and anti- $\beta$-tubulin (T0198, Sigma-Aldrich $\AA$, Madrid, Spain, 1:5000). The Pierce ${ }^{\circledR}$ ECL 2 Western Blotting Substrate (80196, Lumigen Inc., Southfield, MI, USA) coupled with a chemiluminescence system (Amersham Imager 600, GE Healthcare Life Sciences, Buckinghamshire, UK) were used to visualize the blots. The relative amount of signal in each membrane was quantified using the ImageQuant TL v8.1 software (GE Healthcare).

\section{Acrosome reaction assay}

Boar spermatozoa were capacitated for $1 \mathrm{~h}$ and subsequently exposed for $30 \mathrm{~min}$ to $3 \mathrm{ng} / \mathrm{mL}$ progesterone under different experimental conditions, after which the percentage of acrosome-reacted sperm was evaluated by staining with FITC-conjugated peanut agglutinin from Arachis hypogaea (PNA-FITC L7381, Sigma-Aldrich ${ }^{\circledR}$, Madrid, Spain), as previously described [19]. Samples were analyzed under an epifluorescence microscope at $\times 400$ magnification.

\section{Detection of membrane PS translocation}

Translocation of phosphatidylserine (PS) residues to the outer leaflet of the plasma membrane was detected with an Annexin V-Cy3 ${ }^{\text {TM }}$ Apoptosis Detection Kit (Sigma, Madrid, Spain). For this assay, $1 \mu \mathrm{L}$ Annexin $\mathrm{V}$ with $5 \mu \mathrm{L}$ 6-carboxyfluorescein diacetate (6-CFDA) in $450 \mu \mathrm{L}$ of binding buffer (commercial kit) was mixed with $50 \mu \mathrm{L}$ of each sperm sample. After 10 min of incubation in the dark, at room temperature, samples were fixed with $10 \mu \mathrm{L}$ formaldehyde (10\% $v / v$ in DPBS). Each sample was placed on a slide and examined at $\times 400$ magnification 
by epifluorescence microscopy. Viable sperm (6-CFDA+) were visualized in green with a standard fluorescein filter and Annexin+ sperm (labeling PS exposure, Annexin V-Cy3.18+) in red (N2.1 filter; excitation BP 515-560 nm) [20].

\section{Determination of $\left[\mathrm{Ca}^{2+}\right]_{i}$}

Intracellular calcium concentration $\left(\left[\mathrm{Ca}^{2+}\right]_{\mathrm{i}}\right)$ was measured according to a method reported previously [21, 22]. Specifically, spermatozoa were incubated with $2.5 \mu \mathrm{M}$ Fura-2/AM in a buffer medium consisting of $2.7 \mathrm{mM} \mathrm{KCl}, 1.5 \mathrm{mM} \mathrm{KH}{ }_{2} \mathrm{PO}_{4}$, $8.1 \mathrm{mM} \mathrm{Na}_{2} \mathrm{HPO}_{4}, 137 \mathrm{mM} \mathrm{NaCl}, 5.55 \mathrm{mM}$ glucose, and $1 \mathrm{mM}$ pyruvate for $45 \mathrm{~min}$ at $37^{\circ} \mathrm{C}$. The extracellular unloaded Fura- 2 was removed by centrifugation $(700 \times g, 5 \mathrm{~min})$. Washed sperm were resuspended in the same buffer to a concentration of $3 \times 10^{8}$ cells $/ \mathrm{mL}$ and incubated at $37^{\circ} \mathrm{C}$ for $15 \mathrm{~min}$ in the dark. Then, spermatozoa were centrifuged $(700 \times g, 5 \mathrm{~min})$ and resuspended in TALP medium. As a negative control, spermatozoa were also resuspended in DPBS. Fluorescence was monitored using the Jasco FP-6300 spectrofluorometer (Jasco, Madrid, Spain) for a further $30 \mathrm{~min}$. Excitation wavelengths alternated between 340 and $380 \mathrm{~nm}$ with emission held at $510 \mathrm{~nm}$. At the end of the experiments, sperm were lysed with $0.5 \% v / v$ Triton $\mathrm{X}-100$, and then $\mathrm{Ca}^{2+}$ was depleted by addition of $25 \mathrm{mM}$ EGTA. $\left[\mathrm{Ca}^{2+}\right]_{\mathrm{i}}$ was calculated as previously described [23]. For the statistical analysis, the $\mathrm{Ca}^{2+}$ concentration $(\mathrm{nM} / \mathrm{L})$ was recorded from 0 to $1800 \mathrm{~s}$ at 30 -s intervals for every experimental group and replicate. Finally, the mean value during the incubation period was calculated.

\section{Oocyte collection and IVM}

Ovaries from Landrace by Large White gilts were collected at a local slaughterhouse (El Pozo Alimentación S.A., Alhama de Murcia, Murcia, Spain) and transported within 30 min after slaughter to the laboratory in saline solution containing $100 \mu \mathrm{g} /$ $\mathrm{mL}$ kanamycin sulfate at $38.5^{\circ} \mathrm{C}$. Before collecting the cumulusoocyte complexes (COCs), ovaries were washed once in $0.04 \%$ $w / v$ cetrimide solution and twice in saline. COCs from antral follicles (3-6 mm diameter) were washed twice with DPBS supplemented with $1 \mathrm{mg} / \mathrm{mL}$ PVA and $0.005 \mathrm{mg} / \mathrm{mL}$ red phenol, and twice more in maturation medium previously equilibrated for a minimum of $3 \mathrm{~h}$ at $38.5^{\circ} \mathrm{C}$ under $5 \% \mathrm{CO}_{2}$ in air. Groups of $50 \mathrm{COCs}$ with complete and dense cumuli oophori were cultured in $500 \mu \mathrm{L}$ maturation medium for $22 \mathrm{~h}$ at $38.5^{\circ} \mathrm{C}$ under $5 \% \mathrm{CO}_{2}$ in air. Following this incubation, COCs were washed twice in fresh maturation medium without dibutyryl cAMP, eCG, and $\mathrm{hCG}$ and cultured for an additional period of 20-22 h.

\section{IVF and zygote staining}

Following the $44 \mathrm{~h}$ culture in maturation medium, COCs were stripped or not (see "Experimental design") of cumulus cells by pipetting and then washed three times with TALP medium. The IVF medium was previously equilibrated at $38.5^{\circ} \mathrm{C}$ under $5 \%$ $\mathrm{CO}_{2}$ in a four-well dish $(250 \mu \mathrm{L} /$ well $)$, and groups of 50 oocytes were transferred into each well. Semen aliquots $(0.5 \mathrm{~mL})$ from different boars were mixed and subjected to a discontinuous Percoll gradient (45 and 90\% v/v, 740×g, $30 \mathrm{~min}$ ). The resultant sperm pellets were diluted in TALP medium and centrifuged again $(10 \mathrm{~min}$ at $740 \times \mathrm{g})$. After diluting the pellet again in TALP, an aliquot of this suspension was used for IVF, giving a final concentration of $2.5 \times 10^{5}$ spermatozoa $/ \mathrm{mL}$ or $2.5 \times 10^{4}$ spermatozoa/mL, depending on the experiment. The IVF medium was supplemented with NOS inhibitors or NO donor or not supplemented, as described in the experimental design. At $18-20 \mathrm{~h}$ post-insemination, putative zygotes were fixed and stained for evaluation as previously described [3].

\section{Statistical analysis}

The data are presented as the mean \pm standard error of the mean (SEM) and were tested for normality using the Kolmogorov-Smirnov test, and the homogeneity of variance was determined using the Levene test. ANOVA was used for the statistical analysis, and the means were separated using the Tukey test at $P<0.05$. Since the data regarding the acrosome reaction experiment did not satisfy the Kolmogorov-Smirnov and Levene tests, the Kruskal-Wallis test was applied, and treatment average ranks were separated using the stepwise step-down multiple comparisons method [24] at $P<0.05$. The true means of the data, rather than ranked means, are presented. All statistical analyses were conducted using IBM SPSS Statistics for Windows, Version 20.0 (IBM, Armonk, NY, USA).

\section{Experimental design}

\section{Experiment 1: effects of NO on sperm capacitation}

To investigate how the NOS/NO system regulates sperm functionality (Fig. 1: experiment 1), sperm samples were incubated in TALP medium (capacitation medium) for $60 \mathrm{~min}$ at $38.5{ }^{\circ} \mathrm{C}$ and $5 \% \mathrm{CO}_{2}$ with different treatments. Four experimental groups were established according to the treatment used: CONTROL: spermatozoa incubated in the absence of any treatment; GSNO: spermatozoa incubated in the presence of $100 \mu \mathrm{M}$ S-nitrosoglutathione; L-NAME: spermatozoa incubated in the presence of $10 \mathrm{mM} \mathrm{N}^{\mathrm{G}}$-nitroL-arginine methyl ester hydrochloride; and AG: spermatozoa incubated in the presence of $10 \mathrm{mM}$ aminoguanidine hemisulfate salt. These concentrations were chosen based on a literature review $[3,4,25]$.

The experimental groups mentioned above were subjected to the following tests: indirect immunofluorescence (IIF) (to determine NOS localization and Tyr-P in situ), 


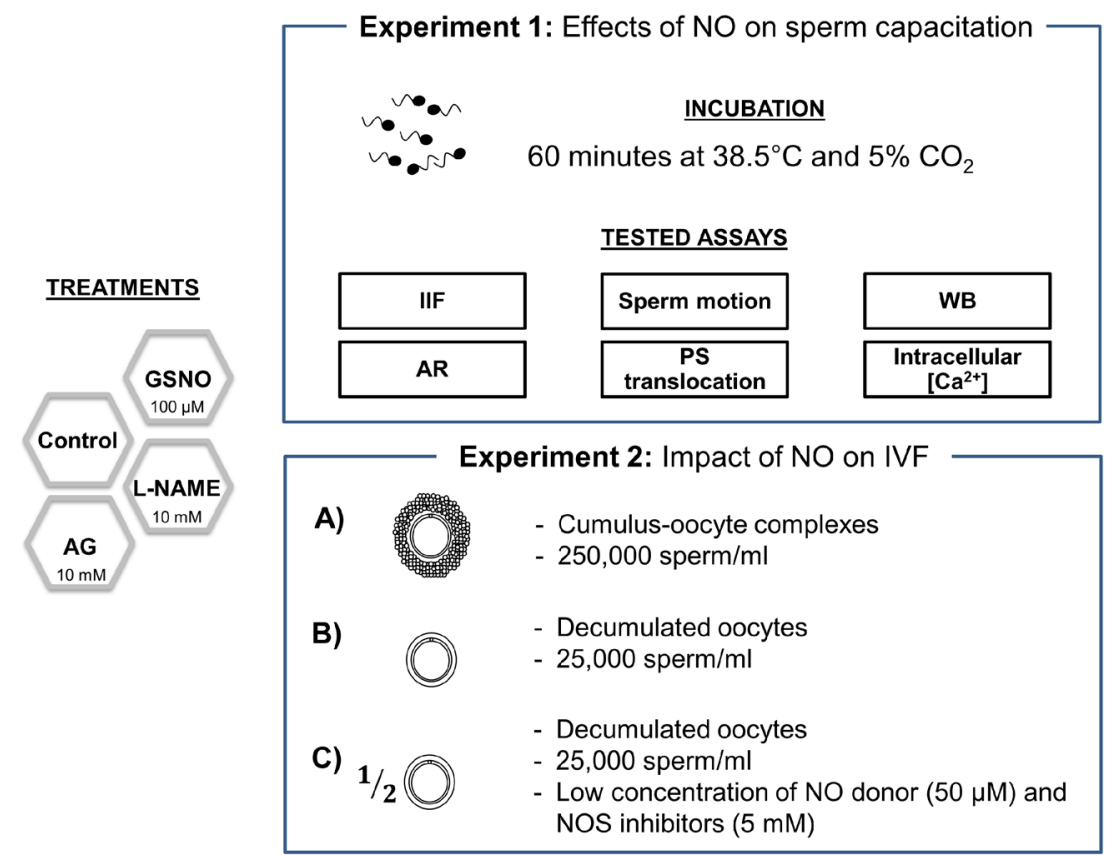

Fig. 1 Analysis of the effects of a NO donor and two NOS inhibitors on sperm capacitation and in vitro fertilization. Experimental design. Experiment 1: Spermatozoa were incubated for $60 \mathrm{~min}$ in the presence or not of these supplements. After that, the following assays were used to evaluated sperm capacitation status: indirect immunofluorescence (IIF), motility assay, Western blotting (WB), acrosome reaction (AR), phosphatidylserine translocation (PS), and measurement of the intracellular calcium concentration; Experiment 2: The in vitro fertilization (IVF) was performed in the presence or not of the NO donor and NOS inhibitors, under three circumstances: (A) Intact cumulus-oocyte complexes and a sperm concentration of 250,000 spermatozoa $/ \mathrm{mL}$, (B) decumulated oocytes and a sperm concentration of 25,000 spermatozoa $/ \mathrm{mL}$, and (C) lower concentrations of the NO donor, NOS inhibitors, and spermatozoa. Neither the oocytes nor the spermatozoa were treated with the NO donor or NOS inhibitors before performing the IVF
Western blotting (WB) (to evaluate the phosphorylation of PKA substrates and Tyr-P), acrosome reaction (AR) assay, PS translocation assay, and measurement of $\left[\mathrm{Ca}^{2+}\right]_{\mathrm{i}}$. However, to avoid sperm agglutination, which hinders cell detection by CASA systems, and since previous studies have reported 30 min sperm incubation under capacitation conditions were sufficient to observe changes in sperm motility parameters [26], this period of time was considered to be suitable to assess the effect of the NOS/ NO system on sperm motion.

\section{Experiment 2: impact of NO on IVF}

To assess how the NOS/NO system modulates the IVF in porcine species, three experiments were performed (Fig. 1: experiment $2 \mathrm{~A}, \mathrm{~B}$, and $\mathrm{C}$ ). All experiments were started using in vitro matured oocytes, and IVF was performed by adding to the medium the abovementioned NO donor and NOS inhibitors. As a control group, IVF was performed in the absence of any treatments. The spermatozoa employed during IVF were not previously treated with these supplements. The percentage of sperm penetration, the sperm number per oocyte, the number of sperm bound to the $\mathrm{ZP}$, and the percentage of male pronucleus formation were determined in all experiments.

\section{Experiment 2A: effects of $\mathrm{NO}$ on the interaction between spermatozoa and $\mathrm{COCs}$}

IVF was performed using COCs that were co-incubated with $2.5 \times 10^{5}$ spermatozoa $/ \mathrm{mL}$. The GSNO was used at a concentration of $100 \mu \mathrm{M}$, whereas for the NOS inhibitors (L-NAME and AG) the concentration was $10 \mathrm{mM}$. This experiment was repeated five times, and a total of 549 oocytes were evaluated.

\section{Experiment 2B: effects of $\mathrm{NO}$ on the interaction between spermatozoa and decumulated oocytes}

Since the cumulus cells also produce NO [27], this second experiment was performed to investigate how the presence/ absence of $\mathrm{NO}$ alters the interaction between sperm and decumulated oocytes. IVF was performed using the same concentrations of NO donor and NOS inhibitors as in experiment A. This experiment was repeated three times, and a total of 258 oocytes were evaluated. 


\section{Experiment 2C: effects of low NOS inhibitor concentration on the interaction between spermatozoa and decumulated oocytes}

The latter assay was developed to evaluate whether there is a dose-dependent effect of the NO donor and NOS inhibitors. For this, IVF was performed using decumulated oocytes, $2.5 \times 10^{4}$ spermatozoa $/ \mathrm{mL}$, and a lower concentration of NO donor and NOS inhibitors $(50 \mu \mathrm{M}$ GSNO and $5 \mathrm{mM}$ for the inhibitors, respectively). This experiment was repeated three times, and a total of 351 oocytes were evaluated.

\section{Results}

\section{Experiment 1: effects of NO on sperm capacitation}

\section{NOS localization}

The three isoforms of NOS, neuronal (nNOS), endothelial (eNOS), and inducible NOS (iNOS), have been identified in different mammalian spermatozoa, including the boar [16]. However, to our knowledge no study has been performed to localize NOSs in porcine ejaculated spermatozoa. Therefore, we used IIF to identify the distribution of these enzymes.

The eNOS was identified in the acrosomal region, although a weak fluorescent signal was also registered in the principal and end piece of the flagellum (Fig. 2). Similarly, the nNOSassociated fluorescence was concentrated in the sperm head region, with a lower fluorescence in the principal and end piece of the flagellum (Fig. 2). Moreover, immunofluorescent iNOS staining was spread over the acrosomal, postacrosomal, and neck region but also in the principal and end pieces of the tail (Fig. 2).

\section{Motility parameters}

The role of NO in sperm motility is controversial, with studies suggesting both a beneficial [28, 29] or detrimental effect [30, 31].

When the CASA evaluation was performed in the present study, at 0 min incubation time (Table 1), none of the motility parameters showed statistical differences $(P>0.05)$. Later, at $30 \mathrm{~min}$ of incubation (Table 1), no differences were found for total motility, progressive motility, VCL, LIN, STR, WOB,

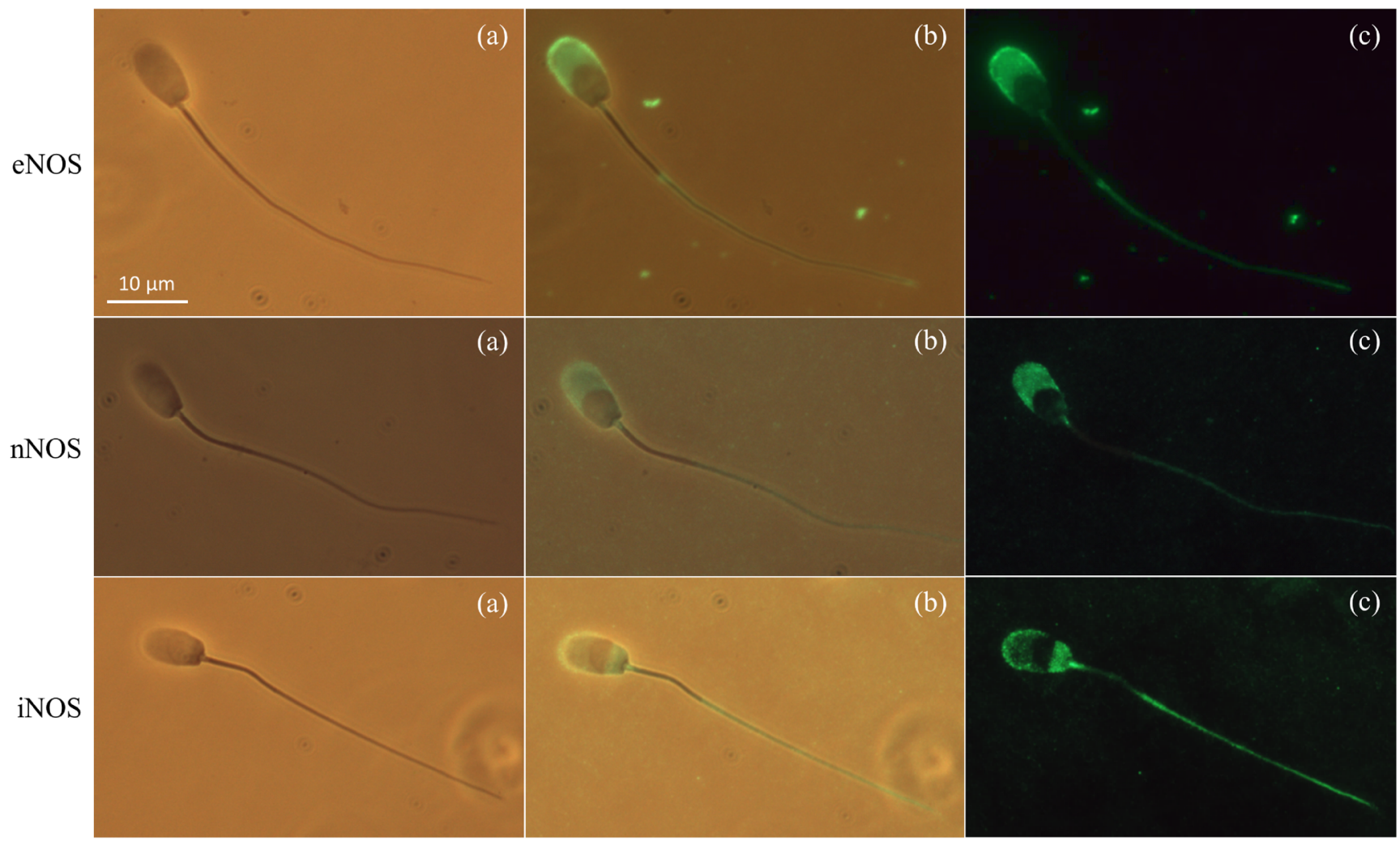

Fig. 2 Localization of NOS isoforms by indirect immunofluorescence. Spermatozoa were fixed, permeabilized, and incubated with specific antieNOS, nNOS, and iNOS primary antibodies, together with a FITClabeled secondary antibody and examined under an epifluorescence microscope at $\times 1000$ magnification. Representative pictures are shown by phase-contrast microscopy (a), merging the phase-contrast image with the green fluorescence pattern (b) and for the immunofluorescent staining (c). The eNOS- and nNOS-associated fluorescence was identified in the sperm head region, with a lower staining in the principal and end pieces of the tail. The iNOS staining pattern was spread over the acrosomal, postacrosomal, and neck region but also in the principal and end pieces of the flagellum 
ALH, or BCF. However, when the VSL was studied, CONTROL and GSNO groups (17.2 \pm 1.3 and $17.9 \pm 1.8$, respectively) were found to be significantly different from AG (11.8 \pm 0.8$)$, but no differences were observed with L-NAME $(16.4 \pm 0.5)$. Continuing the sperm motion analysis, when we analyzed VAP at $30 \mathrm{~min}$, both CONTROL and GSNO showed the highest values $(26.6 \pm 1.8$ and $26.9 \pm 2.6$, respectively), which did not differ from the L-NAME group $(25.5 \pm 0.8)$ but were significantly different from AG $(19.7 \pm 0.9)$.

When looking at the effect of incubation time on the CASA parameters, we observed that at $30 \mathrm{~min}$ of incubation, all treatments showed significant differences compared to their values at time zero for total motility, progressive motility, VCL, VSL, VAP, and BCF. The same difference was found among all treatments in ALH, except for GSNO. Finally, when we compared the values for LIN, STR, and WOB at $T=30 \mathrm{~min}$, the different treatments did not statistically differ from their $T=0 \mathrm{~min}$ counterparts.

\section{Protein kinase A substrates and tyrosine phosphorylation}

The sperm capacitation process involves the early activation of protein kinases and the inactivation of protein phosphatases [32]. It has been reported that NO can modulate this process through the activation of the cAMP/PKA pathway [33] and it is directly involved in tyrosine phosphorylation by modulating both the cAMP/PKA and the extracellular signal-regulated kinase (ERK) pathways (reviewed by [34]).

To determine the effects of the NO donor and NOS inhibitors on boar sperm capacitation, PKAs-P and Tyr-P were analyzed and quantified by WB (Fig. 3). Our results showed that the phosphorylation levels for PKAs-P were significantly lower when using the NOS inhibitors than in the CONTROL group (Fig. 3a, d), whereas the NO donor had no significant effect. Interestingly, the analysis of the relative optical density revealed the presence of three PKA substrate species of approximately 75,55 , and $50 \mathrm{kDa}$ which seemed to possess a specific pattern of phosphorylation (Fig. 3a, e). In detail, the NO donor and NOS inhibitors lowered significantly the degree of phosphorylation in the $\sim 75$ - and $\sim 50-\mathrm{kDa}$ species compared with their levels in the CONTROL $(P<0.05)$, but in the $\sim 55-\mathrm{kDa}$ species this effect was evident only when the capacitation took place in the presence of GSNO and AG $(P<0.05)$.

On the other hand, when considering the phosphorylation levels of tyrosine residues, no significant effects were observed in the presence of both the NO donor and NOS inhibitors (Fig. 3b, f).

\section{Tyr-P detection by IIF}

A crucial event involved in capacitation and the acquisition of fertilizing potential is protein Tyr-P [35]. Different sperm 
(a)

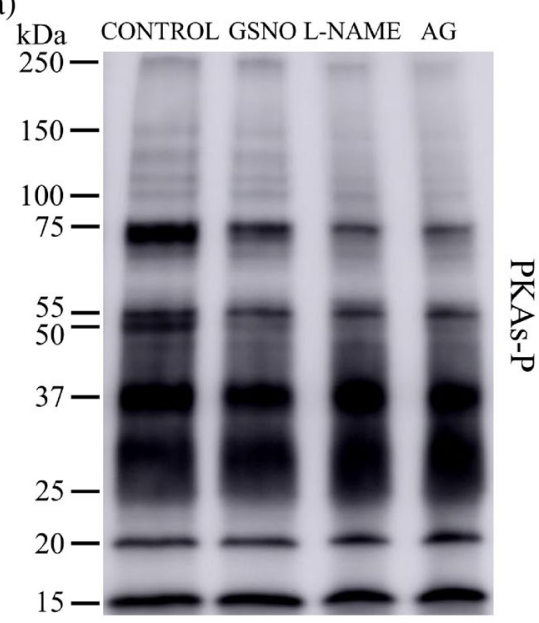

(b)

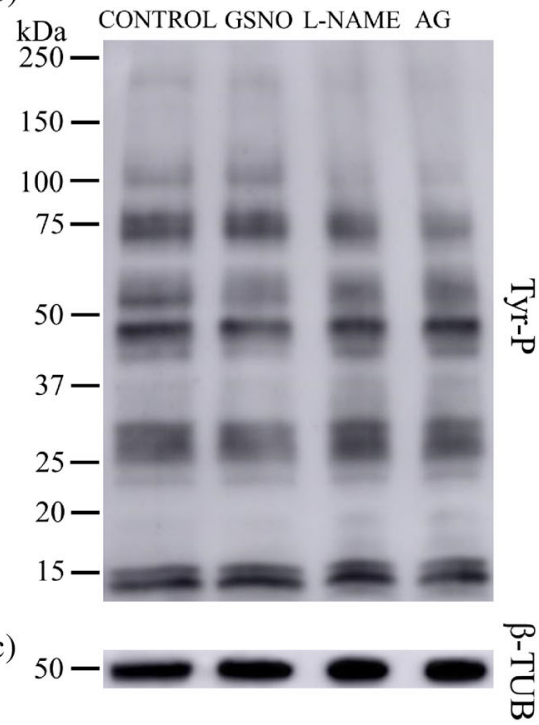

Fig. 3 Effect of GSNO, L-NAME, and AG on PKA substrates (PKAs-P) and tyrosine phosphorylation (Tyr-P). Sperm were incubated for $60 \mathrm{~min}$ under capacitating conditions in the absence of any treatments (CONTROL) or in the presence of GSNO, a NO donor, and L-NAME and AG (both NOS inhibitors). (a, b) Sperm protein extracts were analyzed for phosphorylation by Western blotting using anti-PKAs-P or anti-Tyr-P as first antibodies, respectively. (c) $\beta$-Tubulin was used as a

subpopulations were identified within a sample according to their degree of capacitation and hyperactivation (Table 2). No significant differences were found between groups with regard to the four Tyr-P patterns analyzed $(P>0.05)$.

\section{AR assay}

Progesterone is known to induce the acrosome reaction in capacitated sperm [36], so we determined how this process might be modulated by NO in boar spermatozoa. The results represented in Fig. 4 indicated that the GSNO and AG protein loading control. For signal quantification, each lane was normalized to its $\beta$-tubulin optical density value. (d-f) Relative amount of signal quantified in each membrane using ImageQuant TL v8.1 software for PKAs-P and Tyr-P, respectively. In the $\mathbf{d}$ and $\mathbf{f}$ bar charts, the lane axis represents the total amount of signal quantified in the four groups. Different letters $(\mathrm{a}, \mathrm{b}, \mathrm{c})$ indicate statistically significant differences $(P<0.05)$ between groups

treatments did not influence the percentage of acrosomereacted sperm when compared to the CONTROL. However, L-NAME reduced significantly this percentage $(P<0.05)$.

\section{PS translocation}

In boar spermatozoa, the capacitating agents had been shown to induce rapid changes in the membrane lipid architecture such as the external exposure of PS, which is also commonly recognized as a marker of apoptosis $[37,38]$. As is considered that NO participates in both processes, we decided to 
Table 2 Effects of NO on the immunolocalization of protein Tyr-P

\begin{tabular}{llllll}
\hline Treatment & Number & Pattern I (\%) & Pattern II (\%) & Pattern III (\%) & Pattern IV (\%) \\
\hline CONTROL & 8 & $10.8 \pm 1.9$ & $60.8 \pm 9.2$ & $28.5 \pm 9.4$ & $63.7 \pm 9.7$ \\
GSNO & 8 & $11.2 \pm 2.3$ & $53.2 \pm 9.9$ & $35.9 \pm 9.1$ & $64.3 \pm 10.9$ \\
L-NAME & 8 & $20.0 \pm 6.6$ & $46.4 \pm 11.3$ & $33.6 \pm 11.3$ & $63.0 \pm 10.3$ \\
AG & 8 & $10.9 \pm 2.8$ & $49.4 \pm 11.3$ & $39.8 \pm 10.9$ & $64.6 \pm 8.2$ \\
\hline
\end{tabular}

Pattern I, low capacitation status (non-phosphorylated or head- and/or flagellum-phosphorylated spermatozoa); pattern II, medium capacitation status (equatorial segment or equatorial segment and flagellum-phosphorylated spermatozoa); pattern III, high capacitation status (equatorial segment and head- and/or flagellum-phosphorylated spermatozoa); pattern IV, flagellum phosphorylation independent of phosphorylation in other locations

Number number of replicates investigate the involvement of $\mathrm{NO}$ in the PS translocation during sperm capacitation.

The results (Fig. 5) showed that the NO donor had no significant effect on PS externalization. In fact, both the CONTROL and the GSNO groups reached similar levels of PS translocation (37.67\% and 38\%, respectively). On the other hand, when using the NOS inhibitors, a significant difference was observed only with L-NAME which had a lower PS level than both the GSNO and CONTROL groups $(29.83 \%$; $P<0.05)$. Sperm viability was higher than $50 \%$ in all the treatments (data not shown).

\section{Determination of $\left[\mathrm{Ca}^{2+}\right]_{\mathrm{i}}$}

The regulation of $\mathrm{Ca}^{2+}$ is a fundamental step during the capacitation process [39]; therefore, we monitored its levels before and after our treatments (Fig. 6). During the period prior to the addition of treatments $(600 \mathrm{~s}), \mathrm{Ca}^{2+}$ intake increased throughout the incubation time. Treatment with GSNO did not affect $\left[\mathrm{Ca}^{2+}\right]_{\mathrm{i}}$ versus CONTROL. However, both inhibitors had an

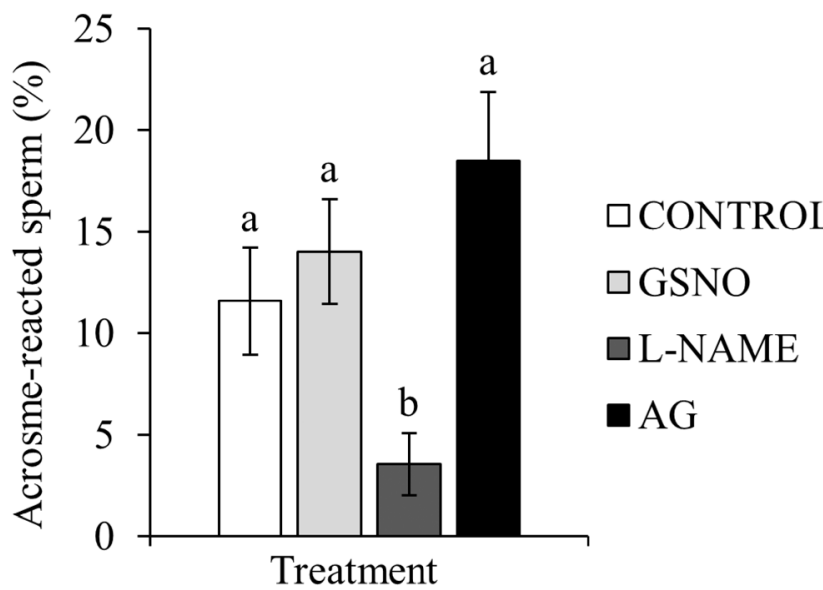

Fig. 4 Effect of GSNO, L-NAME, and AG on the acrosome reaction. After being incubated in capacitating conditions for $60 \mathrm{~min}$ in the absence of any treatments (CONTROL) or in the presence of GSNO, a NO donor, and L-NAME and AG (both NOS inhibitors), the sperm were exposed to $3 \mathrm{ng} / \mathrm{mL}$ progesterone during another $30 \mathrm{~min}$ under the different experimental conditions. Next, the percentage of acrosome-reacted sperm was evaluated by PNA-FITC staining. Different letters $(a, b)$ indicate statistically significant differences $(P<0.05)$ between groups effect on the spermatozoa; in fact, results showed that LNAME reduces abruptly the $\left[\mathrm{Ca}^{2+}\right]_{\mathrm{i}}$ at a basal level, while with AG the reduction is more gradual after its addition.

\section{Experiment 2: impact of NO on IVF}

$\mathrm{NO}$ is one of the components of the environment where fertilization occurs and is generated by oviductal cells [40, 41], oocytes, and cumulus cells $[9,42]$ but also spermatozoa $[15$, $43,44]$. Besides, NO is necessary for sperm capacitation to occur [45]. However, it has been suggested that the sperm NO production is low and most likely these cells encounter sufficient NO levels to support capacitation inside the female genital tract [46]. For these reasons, we studied the effects of NO on the IVF parameters with and without cumulus cells.

\section{Experiment $2 \mathrm{~A}$ : effects of $\mathrm{NO}$ on the interaction between spermatozoa and COCs}

The results (Table 3) showed that the inhibition of NO production affected all IVF parameters. The percentage of oocytes that had been fertilized in the presence of inhibitors decreased. The AG inhibitor reduced the IVF parameters,

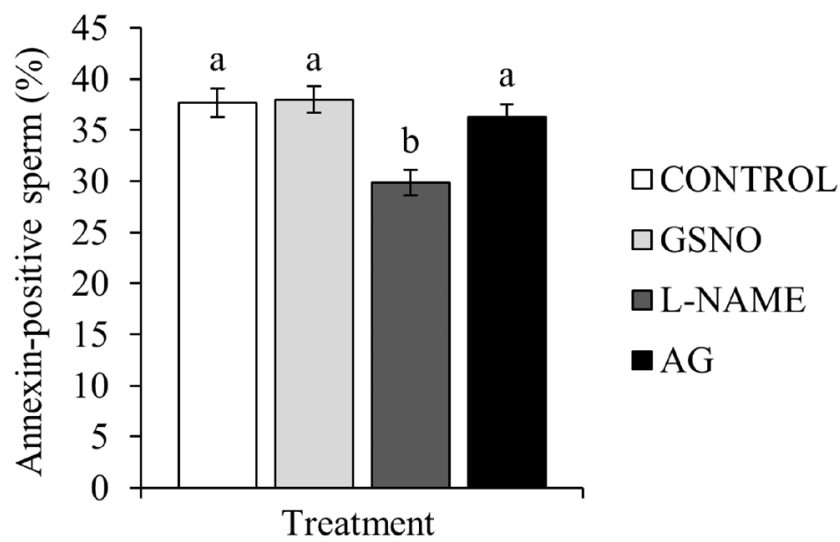

Fig. 5 Effect of GSNO, L-NAME, and AG on PS translocation. Following incubation under capacitating conditions, the translocation of PS residues was analyzed with an Annexin V-Cy3 ${ }^{\mathrm{TM}}$ Apoptosis Detection Kit. Different letters $(\mathrm{a}, \mathrm{b})$ indicate statistically significant differences $(P<0.05)$ between groups 
(a)

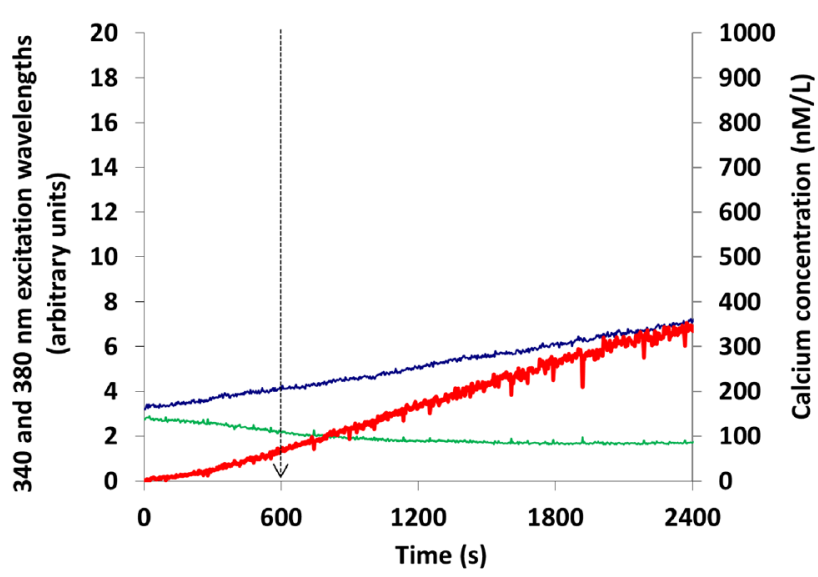

(c)

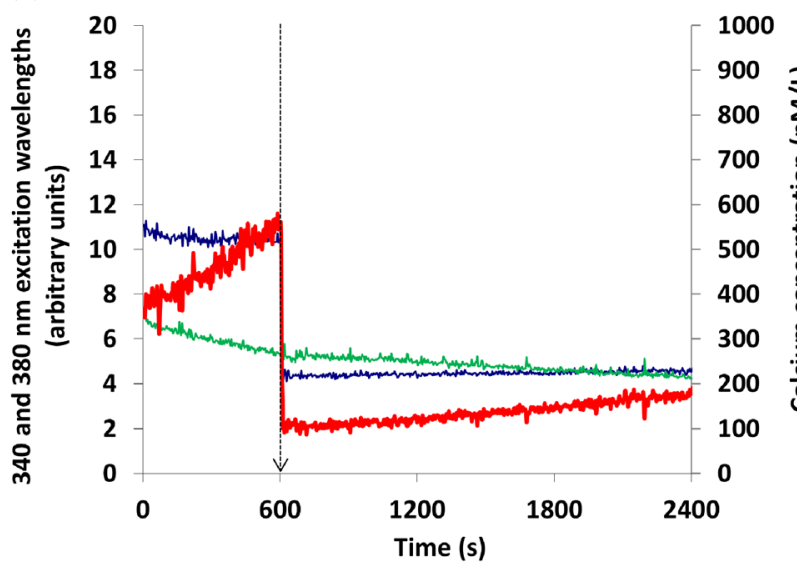

(b)

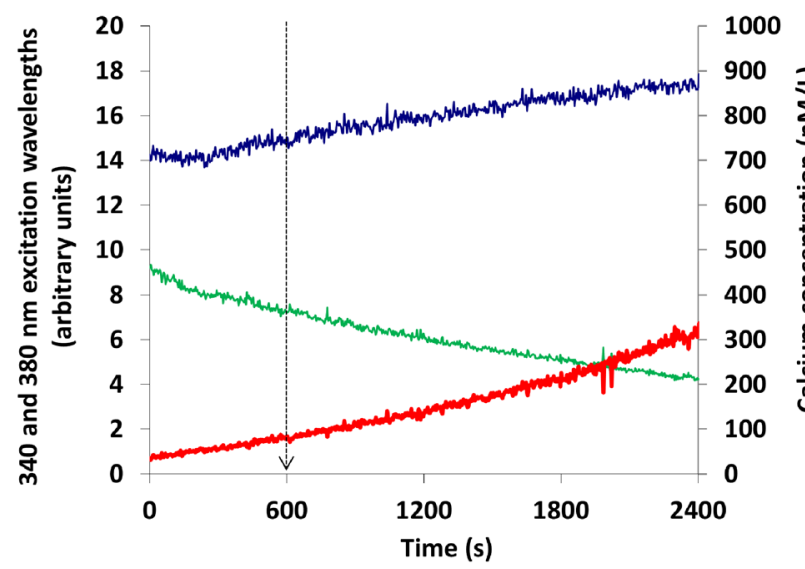

(d)

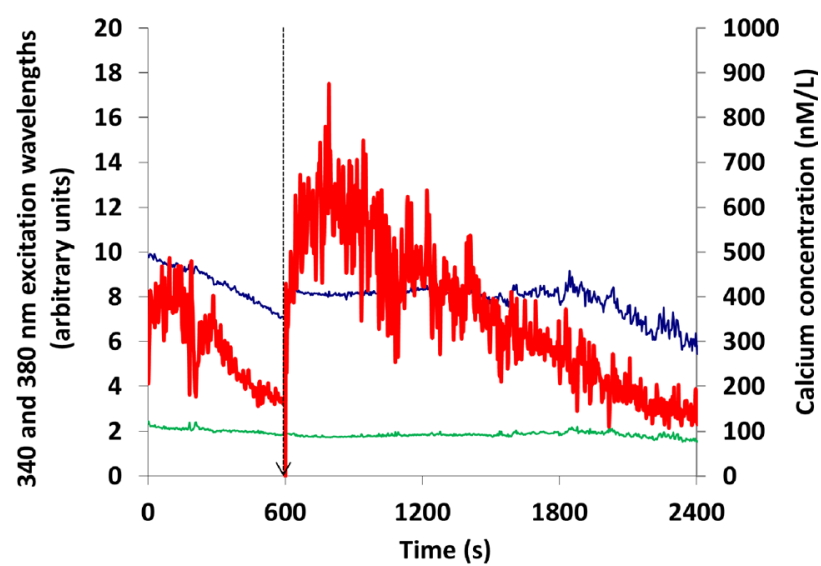

\section{$340 \mathrm{~nm}$}

Fig. 6 Intracellular calcium concentration. Graphs show the measurements collected from the different treatments: a control, b GSNO, c L-NAME, and $\mathbf{d}$ AG. The excitation wavelengths are shown with blue $(340 \mathrm{~nm})$ and green $(380 \mathrm{~nm})$ lines, while the intracellular

but these were higher than in the L-NAME group. As for the number of spermatozoa bound to the ZP and the mean number of spermatozoa per oocyte, we observed that they decreased both with the use of GSNO and with NOS inhibitors. In all the parameters analyzed, the NOS inhibitor with the greatest effect was L-NAME.

\section{$380 \mathrm{~nm}$ Calcium}

calcium concentration is shown by the red line. Fluorescence was measured with the calcium indicator Fura-2/AM and monitored using a spectrofluorometer for $40 \mathrm{~min}$. The system was stabilized for $10 \mathrm{~min}$

(dashed arrow) before adding or not the treatment

\section{Experiment 2B: effects of $\mathrm{NO}$ on the interaction between spermatozoa and decumulated oocytes}

To verify that the effect of the inhibitors was not influenced by the presence of cumulus cells, we decided to evaluate the IVF outcome with denuded oocytes. The obtained results are
Table 3 Effects of NO during IVF with intact cumulus-oocyte complexes

\begin{tabular}{llllll}
\hline Treatment & Number & Penetration $(\%)$ & Sperm/oocyte $(n)$ & Sperm/ZP $(n)$ & MPN formation $(\%)$ \\
\hline CONTROL & 139 & $100 \mathrm{a}$ & $7.8 \pm 0.3 \mathrm{a}$ & $61.9 \pm 3.5 \mathrm{a}$ & 100 \\
GSNO & 128 & $93.0 \pm 2.3 \mathrm{a}$ & $6.5 \pm 0.4 \mathrm{a}, \mathrm{b}$ & $40.8 \pm 2.6 \mathrm{~b}$ & 100 \\
L-NAME & 136 & $1.5 \pm 1 \mathrm{c}$ & $1.5 \pm 0.5 \mathrm{c}$ & $13.8 \pm 1.7 \mathrm{c}$ & 100 \\
AG & 146 & $57.5 \pm 4.1 \mathrm{~b}$ & $2.5 \pm 0.2 \mathrm{~b}, \mathrm{c}$ & $13.7 \pm 1.3 \mathrm{c}$ & 100 \\
\hline
\end{tabular}

Lowercase letters in the same column denote significant differences $(P<0.05)$ between groups

Number number of evaluated oocytes per group, $M P N$ male pronucleus formation 
Table 4 Effects of NO during IVF with denuded oocytes

\begin{tabular}{llllll}
\hline Treatment & Number & Penetration $(\%)$ & Sperm/oocyte $(n)$ & Sperm/ZP $(\%)$ & MPN formation $(\%)$ \\
\hline CONTROL & 61 & $98.4 \pm 1.6 \mathrm{a}$ & $8.3 \pm 0.5 \mathrm{a}$ & $41.2 \pm 2.5 \mathrm{a}$ & $98.3 \pm 0.2 \mathrm{a}$ \\
GSNO & 63 & $96.8 \pm 2.2 \mathrm{a}$ & $8.0 \pm 0.5 \mathrm{a}$ & $25.3 \pm 1.3 \mathrm{~b}$ & $98.4 \pm 0.2 \mathrm{a}$ \\
L-NAME & 66 & 0 & 0 & $0.6 \pm 0.1 \mathrm{c}$ & 0 \\
AG & 68 & $17.6 \pm 4.6 \mathrm{c}$ & $1.8 \pm 0.3 \mathrm{~b}$ & $5 \pm 0.9 \mathrm{c}$ & $100 \mathrm{a}$ \\
\hline
\end{tabular}

Lowercase letters in the same column denote significant differences $(P<0.05)$ between groups

Number number of evaluated oocytes per group, $M P N$ male pronucleus formation shown in Table 4, in which we can observe that there was no penetration when the IVF medium was supplemented with LNAME and was very low when using AG. The addition of the NO donor to the fertilization medium had no significant effect on the percentage of penetration with respect to the CONTROL group. As for the spermatozoa adhered to the $\mathrm{ZP}$, both the NO donor and the NOS inhibitors lowered this parameter when compared to the CONTROL.

\section{Experiment 2C: effects of low NOS inhibitors concentration on the interaction between spermatozoa and decumulated oocytes}

Furthermore, we decided to analyze if IVF results would be modified by decreasing the inhibitor concentration, as well as that of spermatozoa (which synthesize NO). We observed (Table 5) that the inhibitors continued to have the same effect on all analyzed parameters. Also, with a lower sperm concentration $\left(2.5 \times 10^{4}\right.$ spermatozoa $\left./ \mathrm{mL}\right)$, the penetration percentage in the CONTROL and in the GSNO groups was lower than in our previous experiments, in which a 10-fold higher sperm concentration was used.

\section{Discussion}

The participation of the NOS/NO system in the reproductive function has been widely demonstrated [34]. NO has a dual role. Low amounts, generated under physiological conditions, seem to be beneficial for sperm functions [7, 28], but the excessive synthesis of NO, which takes place under in vitro fertilization conditions, could be detrimental for sperm function [47]. For that, the amount of NO in the fertilization media is variable and depends on the cumulus cells or sperm production, which could modify the capacitation process and the IVF outcome. The present study is, to the best of our knowledge, the first one to tackle both these aspects in porcine species, in the effort to obtain more insight on NO-mediated gamete interaction in vitro in this species.

NO synthesis takes place via L-arginine oxidation by three distinct NOS isoforms: neuronal (nNOS), endothelial (eNOS), also known as the constitutive isoforms, and the inducible NOS (iNOS) [48]. Numerous studies have been conducted to determine the presence and localization of these enzymes in sperm from several species [34] with slight differences between them [15, 44, 49]. However, the localization in boar sperm has not been described. We encountered a similar distribution between eNOS and nNOS, mostly in the sperm head region, whereas the immunofluorescent iNOS staining was spread on almost all sperm regions. This pattern could have a physiological significance, and it may suggest that the constitutive NOSs could be closely related to the activation of key pathways which leads to the capacitation [49], while the general distribution of the iNOS immunostaining might be connected to inflammatory processes in the male reproductive tract [50-52], rather than in the acquiring of the fertilization ability. We do not know if the NOS pattern exhibited by boar sperm changes during incubation in vitro, but this aspect should be addressed in future studies.

In the porcine species, research was focused mainly to address the involvement of NO in the promotion of capacitation $[16,53-55]$, lacking studies addressing the effect on sperm
Table 5 Effects of NO during IVF with lower concentrations of sperm, NO donor, and NOS inhibitors

\begin{tabular}{llllll}
\hline Treatment & Number & Penetration $(\%)$ & Sperm/oocyte $(n)$ & Sperm/ZP $(n)$ & MPN formation (\%) \\
\hline CONTROL & 80 & $78.7 \pm 4.6 \mathrm{a}$ & $5.5 \pm 0.9$ & $42.8 \pm 4.6 \mathrm{a}$ & $96.8 \pm 2.2$ \\
GSNO & 76 & $77.6 \pm 4.8 \mathrm{a}$ & $7.2 \pm 0.9$ & $36.4 \pm 3.9 \mathrm{a}$ & 100 \\
L-NAME & 102 & $1.9 \pm 1.4 \mathrm{~b}$ & $1.0 \pm 0$ & $5.0 \pm 0.6 \mathrm{~b}$ & 100 \\
AG & 93 & $3.2 \pm 1.8 \mathrm{~b}$ & $1.0 \pm 0$ & $4.9 \pm 0.8 \mathrm{~b}$ & 100 \\
\hline
\end{tabular}

Lowercase letters in the same column denote significant differences $(P<0.05)$ between groups

Number number of evaluated oocytes per group, $M P N$ male pronucleus formation 
motility. In this sense, our results showed that despite that no differences were found at the beginning of the incubation, medium supplementation with AG, which selectively inhibits iNOS [56], significantly reduced VSL and VAP at $30 \mathrm{~min}$ of incubation. These results are completely opposite from the ones reported by Alizadeh et al. in varicocelized rats [57], where AG was shown to improve sperm motility and mitochondrial membrane potential. But both results are not comparable as their experimental design included an $\mathrm{AG}$ injection daily for 10 weeks, while we treated ejaculated sperm for $30 \mathrm{~min}$. Nevertheless, it is worth noting that the reduction in these parameters has been linked to low breeding performance in porcine species [58]. In relation to the lack of a visible effect of the GSNO supplementation on sperm motility, this result agrees with Zini et al. [46] in human sperm, who demonstrated that a low concentration of a NO-releasing agent $(0.1 \mathrm{mM})$, equal to the one we used, had no effect on the percentage of sperm motility or of hyperactivation. In regard to L-NAME, we did not find any significant difference in our experiment, while the addition of $10 \mathrm{mM} \mathrm{L-NAME}$ was reported to inhibit bull sperm progressive motility [25]. However, as some studies describe, this inhibitor is more likely to exert its effect on the inhibition of sperm capacitation rather than affecting sperm motility.

The phosphorylation levels of PKA substrates and tyrosine are known to be indicative of sperm capacitation status [26] and evidence confirms that NO regulates both serine/ threonine [59] and tyrosine phosphorylation [60]. Our data suggest that the use of GSNO as a NO donor had no significant effect on the total level of phospho-PKA substrates (i.e., serine and threonine phosphorylation) and phosphorylation of tyrosine residues. On the contrary, Herrero and colleagues [60] have suggested that NO-releasing molecules might accelerate the capacitation process. In fact, when using sodium nitroprusside (SNP) during human sperm capacitation, an increase in tyrosine phosphorylation was observed. Similarly, Thundathil et al. [59] reported that the NO generated by spermine NONOate leads to an increase in the phosphorylation levels of the threonine-glutamine-tyrosine motif in two different human sperm proteins. However, we observed a specific phosphorylation pattern for three PKA substrate species, $\sim 75, \sim 55$, and $\sim 50 \mathrm{kDa}$, which showed a lower degree of phosphorylation in the presence of GSNO. These data also seem to be in contrast with a previous work [61] and might be explained by the difference in the capacitation time $(60 \mathrm{~min}$ in boar vs $240 \mathrm{~min}$ in human vs $90 \mathrm{~min}$ in mouse spermatozoa) and the species used, since the dynamics of serine/ threonine phosphorylation are species-specific $[62,63]$. On the other hand, our results showed that the inhibition of NO synthesis leads to a decrease in the levels of phospho-PKA substrates. This effect was more evident in the $\sim 75$ - and $\sim 50$ $\mathrm{kDa}$ species. We speculate that these bands might contain proteins targeted for tyrosine phosphorylation, after they have been phosphorylated in serine/threonine by PKA in the presence of NO [64] to allow the correct development of the capacitation process.

NO is able to determine an increase in Tyr-P via the sGCcGMP signaling pathway [34] at nanomolar levels [65] and the lack of NO due to NOS inhibition is correlated with lower levels of Tyr-P $[60,66]$. However, according to our data, the NOS inhibitors had no effect on Tyr-P. It is possible that neither the NO donor nor the inhibitors used in our study were able to increase or lower Tyr-P because the low endogenous NO levels were enough to induce it [67]. This result is supported by our Tyr-P immunolocalization data, where no differences were observed between treatments.

At a molecular level, the AR shares a significant overlap with molecular events of capacitation [48] and both processes have been shown to be regulated by NO [46]. When incubating boar spermatozoa with exogenous NO, we did not observe any differences when compared to CONTROL. Other studies, however, report the NO donor's ability to increase the percentage of acrosome-reacted sperm in boars [54] and different species (human [68], buffalo [69], and mouse [61]). This discrepancy might be explained by the different NO-releasing molecule used in these studies, which have different kinetics for NO generation [60]. Interestingly, when adding L-NAME to the incubation medium, the AR was significantly reduced in our study. This finding is consistent with previous studies in boar [16, 54], human [60], and hamster spermatozoa [70], which confirms that endogenous NO is necessary for spermatozoa to achieve their full fertilizing ability [60].

The translocation of PS is considered a physiological event during the capacitation process but also a sign of cellular damage $[20,38]$. During sperm capacitation, the bicarbonatestimulated protein phosphorylation pathway leads to the activation of phospholipid scramblase $[37,71]$ which results in the exposure of PS at the outer membrane surface [37]. Our results showed that the use of GSNO did not induce apoptoticlike changes in sperm when compared to CONTROL. This contrasts the findings of Moran et al. [72], and the reason might be the different methodological approach, namely, the use of a different NO-releasing compound and its concentration (100 $\mu \mathrm{M}$ GSNO vs $400 \mu \mathrm{M}$ SNP). It has been reported that an increase in Annexin-positive spermatozoa is related to capacitation in boar semen [72] and that NOS inhibitors prevent capacitation [70]. This is in accordance with our observations regarding the NOS inhibitor L-NAME, which lowered significantly the percentage of Annexin-positive sperm.

In sperm, $\left[\mathrm{Ca}^{2+}\right]_{\mathrm{i}}$ changes through two routes, either $\mathrm{Ca}^{2+}$ ions are released from internal stores or transported into the cell by sperm-specific membrane channels $[62,73]$. Previous studies have shown that $\mathrm{NO}$ can interact with different $\mathrm{Ca}^{2+}$ routes [74-76] also in spermatozoa [27]. In this sense, we have investigated how the NOS/NO system regulates $\left[\mathrm{Ca}^{2+}\right]_{i}$ in porcine sperm. The results showed changes only when 
NOS inhibitors were used, L-NAME having the most potent effect. We hypothesized that in its presence, $\mathrm{Ca}^{2+}$ ions get expelled quickly from spermatozoa mainly through the $\mathrm{Ca}^{2+}$ efflux pump, plasma membrane calcium ATPase 4 (PMCA4) $[77,78]$, which is known to regulate NO signaling by downregulating the NOSs in murine sperm [77]. When using LNAME, the PMCA4-NOS interaction might not have taken place, which in turn might have led PMCA4 to extrude the cytosolic $\mathrm{Ca}^{2+}$. Further experiments are needed to test this hypothesis.

Although it also affects the rest of the NOS isoforms, AG preferentially inhibits the iNOS isoform [79], which could explain why the reduction of $\left[\mathrm{Ca}^{2+}\right]_{\mathrm{i}}$ when adding this inhibitor is not as pronounced as it is with L-NAME. Our results suggest that in the beginning the $\mathrm{Ca}^{2+}$ output is compensated by the $\mathrm{Ca}^{2+}$ which comes from the internal stores causing the increase in $\left[\mathrm{Ca}^{2+}\right]_{i}$. Once the internal stores are empty, $\left[\mathrm{Ca}^{2+}\right]_{\mathrm{i}}$ begins to decrease until reaching levels similar to those obtained with L-NAME. No significant differences were observed in relation to the GSNO supplementation, suggesting that NO contributes to the gradual increase in $\left[\mathrm{Ca}^{2+}\right]_{\mathrm{i}}$. This effect may be observed as a consequence of NO-mediated Snitrosylation on sperm $\mathrm{Ca}^{2+}$ stores such as the ryanodine receptors [27, 80, 81]. Clearly, more experiments will be needed to confirm these data.

We have shown that the inhibition of NO synthesis, mainly by L-NAME, affects protein phosphorylation, acrosome reaction, and $\mathrm{Ca}^{2+}$ fluxes. However, the best test that indirectly evaluates sperm capacitation is the IVF [82], because only fully capacitated sperm can bind to the ZP, undergo acrosome reaction, and penetrate the oocyte's plasma membrane. Consequently, we studied the modulation of sperm capacitation by NO in an IVF system under three circumstances: (i) IVF with cumulus-oocyte complexes, (ii) IVF with denuded oocytes, and (iii) denuded oocytes with reduced concentrations of NO donor and inhibitors. The results showed that under these three circumstances the tendency was the same; that is, in the presence of NOS inhibitors, the number of spermatozoa adhered to the ZP and the percentage of penetrated oocytes, and the mean number of spermatozoa per penetrated oocyte decreased. In addition, this effect was more pronounced when the L-NAME inhibitor was used.

Although it was proved that spermatozoa can synthesize NO, the evidence that its synthesis is sufficient to be physiologically important is not very clear [83]. For this reason, the first part of our IVF experiments was done with oocytes together with cumulus cells which generate significant amounts of NO and, therefore, participate in the processes of capacitation and fertilization [27]. Under these circumstances, we observed that both NOS inhibitors (L-NAME and AG) decreased the penetration rate but in a different way: $A G$ reduced this parameter to half versus CONTROL, while L-NAME reduced it almost to zero. This may lead us to believe that the inhibitory effect of AG on NO production from cumulus cells or spermatozoa is not total since AG is a less potent inhibitor of the constitutive isoforms [79]. For this reason, enough NO could still be produced by the constitutive isoforms thus allowing the capacitation in some spermatozoa.

In 2008, Hou et al. [54] observed that the addition of LNAME inhibited NO production by $30-40 \%$, impairing the ability of spermatozoa to undergo the acrosome reaction. However, in our experiment, the addition of L-NAME decreased the penetration rate almost to zero, the AR levels being also significantly reduced. Therefore, in these conditions we could assume that NO synthesis was almost completely abolished, which might be explained by the fact that the inhibitor concentration used in our study was higher than the one used by Hou and colleagues.

Since cumulus cells could be differently sensible to NOS inhibitors, we considered performing IVF using denuded oocytes. The results showed a big decrease in the penetration rate with the AG inhibitor and zero penetration with L-NAME, so in the first experiment, the cumulus cells even in the presence of inhibitors were able to generate NO to allow sperm capacitation and fertilization. Finally, with the purpose of checking if the results previously obtained were due to the high concentration of NO donor and NOS inhibitors or a high number of sperm in the medium, we decided to reduce these parameters. We observed that the penetration in the CONTROL and GSNO groups decreased, but it did not increase in the inhibitor groups. We can assume that NO sperm production continued being abolished. On the other hand, Leal et al. [25] obtained a penetration rate of $70 \%$ in bovine with the same LNAME concentration. Perhaps in this species, the constitutive NOSs in sperm are less sensible to this inhibitor. In other species, such as human [10] or mouse [8], it has been shown that the inhibitor effects of L-NAME were dose-dependent and the oocyte penetration could be affected even without modifications in the sperm capacitation parameters [10]. In contrast to Francavilla et al. [10], who observed that constitutive NOS play a role in the human sperm's capacity to fuse with oocyte but not in the ZP binding, our results showed that even though the binding was not completely abolished, it decreased, so we can assume that the primary binding is less affected by NO absence. Interestingly, the NO donor GSNO lowered significantly the number of sperm bound to the ZP when compared with the CONTROL in either presence or absence of cumulus cells. A similar finding was reported by $\mathrm{Wu}$ et al. [84], suggesting that physiologic levels of NO are required for the binding process.

\section{Conclusions}

During the past years, many studies focused on the role of NO in the physiology of reproduction. However, a clear 
investigation addressing the ability of the NOS/NO duo to modulate/affect in vitro both sperm capacitation and their interaction with the oocyte has been lacking in boars. The present work strongly suggests the importance of a delicate regulation of NOS enzymes during capacitation and IVF. NOS distribution, evidenced here for the first time in porcine spermatozoa, might be linked to key factors in the acquisition of a full fertilizing ability, such as protein phosphorylation, acrosome reaction, and intracellular $\mathrm{Ca}^{2+}$ fluxes. Our data shows how both sperm and cumulus-oocyte derived NO is required for successful IVF. Nevertheless, further studies should provide more information on these mechanisms in the attempt to solve IVF issues in porcine species, such as polyspermy.

Funding This study was supported by H2020 MSC-ITN-EJD 675526 REP-BIOTECH, the Spanish Ministry of Economy and Competitiveness (MINECO), and the European Regional Development Fund (FEDER), Grant AGL2015-66341-R, and by a grant ESPDOC17/ 33 (to Jon Romero-Aguirregomezcorta) from the University of the Basque Country (UPV/EHU, Spain).

\section{Compliance with ethical standards}

The study was carried out following the Spanish Policy for Animal Protection RD 53/2013, which meets European Union Directive 2010/63/UE on animal protection. The Ethics Committee of Animal Experimentation of the University of Murcia and the Animal Production Service of the Agriculture Department of the Region of Murcia (Spain) (ref. no. A13160609) approved the procedures performed in this work.

Conflict of interest The authors declare that they have no conflict of interest.

Open Access This article is distributed under the terms of the Creative Commons Attribution 4.0 International License (http:// creativecommons.org/licenses/by/4.0/), which permits unrestricted use, distribution, and reproduction in any medium, provided you give appropriate credit to the original author(s) and the source, provide a link to the Creative Commons license, and indicate if changes were made.

\section{References}

1. Aitken RJ. Reactive oxygen species as mediators of sperm capacitation and pathological damage. Mol Reprod Dev. 2017;84:1039-52.

2. Wang J, He Q, Yan X, Cai Y, Chen J. Effect of exogenous nitric oxide on sperm motility in vitro. Biol Res. 2014;47:44.

3. Romero-Aguirregomezcorta J, Santa ÁP, García-Vázquez FA, Coy $\mathrm{P}$, Matás C. Nitric oxide synthase (NOS) inhibition during porcine in vitro maturation modifies oocyte protein S-nitrosylation and in vitro fertilization. PLoS One. 2014;9:e115044.

4. Lefièvre L, Chen Y, Conner SJ, Scott JL, Publicover SJ, Ford WCL, et al. Human spermatozoa contain multiple targets for protein $\mathrm{S}$ nitrosylation: an alternative mechanism of the modulation of sperm function by nitric oxide? Proteomics. 2007;7:3066-84.

5. Herrero MB, Viggiano JM, Pérez Martínez S, de Gimeno MF. Evidence that nitric oxide synthase is involved in progesterone- induced acrosomal exocytosis in mouse spermatozoa. Reprod Fertil Dev. 1997;9:433-9.

6. Gawronska B, Bodek G, Ziecik AJ. Distribution of NADPHdiaphorase and nitric oxide synthase (NOS) in different regions of porcine oviduct during the estrous cycle. J Histochem Cytochem. 2000;48:867-75.

7. Sengoku K, Tamate K, Yoshida T, Takaoka Y, Miyamoto T, Ishikawa M. Effects of low concentrations of nitric oxide on the zona pellucida binding ability of human spermatozoa. Fertil Steril. 1998;69:522-7.

8. Herrero MB, Viggiano JM, Pérez Martínez S, de Gimeno MF. Effects of nitric oxide synthase inhibitors on the outcome of in vitro fertilization in the mouse. Reprod Fertil Dev. 1996;8:301-4.

9. Reyes R, Vázquez MLS, Delgado NM. Detection and bioimaging of nitric oxide in bovine oocytes and sperm cells. Arch Androl. 2004;50:303-9.

10. Francavilla F, Santucci R, Macerola B, Ruvolo G, Romano R. Nitric oxide synthase inhibition in human sperm affects spermoocyte fusion but not zona pellucida binding. Biol Reprod. 2000;63:425-9.

11. Doshi SB, Khullar K, Sharma RK, Agarwal A. Role of reactive nitrogen species in male infertility. Reprod Biol Endocrinol. 2012;10:109.

12. Gadea J, Matás C. Sperm factors related to in vitro penetration of porcine oocytes. Theriogenology. 2000;54:1343-57.

13. Petters RM, Wells KD. Culture of pig embryos. J Reprod Fertil Suppl. 1993;48:61-73.

14. Rath D, Long CR, Dobrinsky JR, Welch GR, Schreier LL, Johnson LA. In vitro production of sexed embryos for gender preselection: high-speed sorting of X-chromosome-bearing sperm to produce pigs after embryo transfer. J Anim Sci. 1999;77:3346-52.

15. Meiser H, Schulz R. Detection and localization of two constitutive NOS isoforms in bull spermatozoa. Anat Histol Embryol. 2003;32: $321-5$.

16. Aquila S, Giordano F, Guido C, Rago V, Carpino A. Nitric oxide involvement in the acrosome reaction triggered by leptin in pig sperm. Reprod Biol Endocrinol. 2011;9:133.

17. Matás C, Vieira L, García-Vázquez FA, Avilés-López K, LópezÚbeda R, Carvajal JA, et al. Effects of centrifugation through three different discontinuous Percoll gradients on boar sperm function. Anim Reprod Sci. 2011;127:62-72.

18. Navarrete FA, García-Vázquez FA, Alvau A, Escoffier J, Krapf D, Sánchez-Cárdenas C, et al. Biphasic role of calcium in mouse sperm capacitation signaling pathways. J Cell Physiol. 2015;230: $1758-69$.

19. Kawano N, Araki N, Yoshida K, Hibino T, Ohnami N, Makino M, et al. Seminal vesicle protein SVS2 is required for sperm survival in the uterus. Proc Natl Acad Sci U S A. 2014;111:4145-50.

20. Martí E, Pérez-Pé R, Colás C, Muiño-Blanco T, Cebrián-Pérez JA. Study of apoptosis-related markers in ram spermatozoa. Anim Reprod Sci. 2008;106:113-32.

21. Tardif S, Dubé C, Bailey JL. Porcine sperm capacitation and tyrosine kinase activity are dependent on bicarbonate and calcium but protein tyrosine phosphorylation is only associated with calcium. Biol Reprod. 2003;68:207-13.

22. Matás C, Sansegundo M, Ruiz S, García-Vázquez FA, Gadea J, Romar R, et al. Sperm treatment affects capacitation parameters and penetration ability of ejaculated and epididymal boar spermatozoa. Theriogenology. 2010;74:1327-40.

23. Grynkiewicz G, Poenie M, Tsien RY. A new generation of $\mathrm{Ca} 2+$ indicators with greatly improved fluorescence properties. J Biol Chem. 1985;260:3440-50.

24. Campbell G, Skillings JH. Nonparametric stepwise multiple comparison procedures. J Am Stat Assoc. 1985;80:998-1003.

25. Leal ACMS, Caldas-Bussiere MC, de Carvalho CSP, Viana KS, Quirino CR. Role of nitric oxide on quality of freshly ejaculated 
bull spermatozoa during heparin-induced in vitro capacitation. Anim Reprod Sci. 2009;116:38-49.

26. Soriano-Úbeda C, García-Vázquez FA, Romero-Aguirregomezcorta $\mathrm{J}$, Matás C. Improving porcine in vitro fertilization output by simulating the oviductal environment. Sci Rep. 2017;7:43616.

27. Machado-Oliveira G, Lefievre L, Ford C, Herrero MB, Barratt C, Connolly TJ, et al. Mobilisation of $\mathrm{Ca} 2+$ stores and flagellar regulation in human sperm by S-nitrosylation: a role for NO synthesised in the female reproductive tract. Development. 2008;135:3677-86.

28. Donnelly ET, Lewis SE, Thompson W, Chakravarthy U. Sperm nitric oxide and motility: the effects of nitric oxide synthase stimulation and inhibition. Mol Hum Reprod. 1997;3:755-62.

29. Lewis SE, Donnelly ET, Sterling ES, Kennedy MS, Thompson W, Chakravarthy U. Nitric oxide synthase and nitrite production in human spermatozoa: evidence that endogenous nitric oxide is beneficial to sperm motility. Mol Hum Reprod. 1996;2:873-8.

30. Rosselli M, Dubey RK, Imthurn B, Macas E, Keller PJ. Effects of nitric oxide on human spermatozoa: evidence that nitric oxide decreases sperm motility and induces sperm toxicity. Hum Reprod. 1995;10:1786-90.

31. Weinberg JB, Doty E, Bonaventura J, Haney AF. Nitric oxide inhibition of human sperm motility. Fertil Steril. 1995;64:408-13.

32. Battistone MA, Da Ros VG, Salicioni AM, Navarrete FA, Krapf D, Visconti PE, et al. Functional human sperm capacitation requires both bicarbonate-dependent PKA activation and down-regulation of Ser/Thr phosphatases by Src family kinases. Mol Hum Reprod. 2013;19:570-80.

33. Belén Herrero $\mathrm{M}$, Chatterjee $\mathrm{S}$, Lefièvre L, De Lamirande E, Gagnon C. Nitric oxide interacts with the cAMP pathway to modulate capacitation of human spermatozoa. Free Radic Biol Med. 2000;29:522-36.

34. Staicu F-D, Matas Parra C (2017) Nitric oxide: key features in spermatozoa. In: Saravi SSS, editor. Nitric Oxide Synthase Simple Enzyme-Complex Roles. InTech. p. 137-54

35. Töpfer-Petersen E. Molecules on the sperm's route to fertilization. J Exp Zool. 1999;285:259-66.

36. de Lamirande E, Leclerc P, Gagnon C. Capacitation as a regulatory event that primes spermatozoa for the acrosome reaction and fertilization. Mol Hum Reprod. 1997;3:175-94.

37. Gadella BM, Harrison RAP. Capacitation induces cyclic adenosine 3',5'-monophosphate-dependent, but apoptosis-unrelated, exposure of aminophospholipids at the apical head plasma membrane of boar sperm cells. Biol Reprod. 2002;67:340-50.

38. Aitken RJ, Baker MA, Nixon B. Are sperm capacitation and apoptosis the opposite ends of a continuum driven by oxidative stress? Asian J Androl. 2015;17:633-9.

39. Abou-haila A, Tulsiani DRP. Signal transduction pathways that regulate sperm capacitation and the acrosome reaction. Arch Biochem Biophys. 2009;485:72-81.

40. Rosselli M, Dubey RK, Rosselli MA, Macas E, Fink D, Lauper U, et al. Identification of nitric oxide synthase in human and bovine oviduct. Mol Hum Reprod. 1996;2:607-12.

41. Lapointe J, Roy M, St-Pierre I, Kimmins S, Gauvreau D, MacLaren LA, et al. Hormonal and spatial regulation of nitric oxide synthases (NOS) (neuronal NOS, inducible NOS, and endothelial NOS) in the oviducts. Endocrinology. 2006;147:5600-10.

42. Tao Y, Fu Z, Zhang M, Xia G, Yang J, Xie H. Immunohistochemical localization of inducible and endothelial nitric oxide synthase in porcine ovaries and effects of $\mathrm{NO}$ on antrum formation and oocyte meiotic maturation. Mol Cell Endocrinol. 2004;222:93-103.

43. Herrero MB, Goin JC, Boquet M, Canteros MG, Franchi AM, Perez Martinez S, et al. The nitric oxide synthase of mouse spermatozoa. FEBS Lett. 1997;411:39-42.

44. O’Bryan MK, Zini A, Cheng CY, Schlegel PN. Human sperm endothelial nitric oxide synthase expression: correlation with sperm motility. Fertil Steril. 1998;70:1143-7.
45. O'Flaherty C, de Lamirande E, Gagnon C. Positive role of reactive oxygen species in mammalian sperm capacitation: triggering and modulation of phosphorylation events. Free Radic Biol Med. 2006;41:528-40.

46. Zini A, De Lamirande E, Gagnon C. Low levels of nitric oxide promote human sperm capacitation in vitro. J Androl. 1995;16: 424-31.

47. O'Flaherty C, Rodriguez P, Srivastava S. L-Arginine promotes capacitation and acrosome reaction in cryopreserved bovine spermatozoa. Biochim Biophys Acta. 1674;2004:215-21.

48. Buzadzic B, Vucetic M, Jankovic A, Stancic A, Korac A, Korac B, et al. New insights into male (in)fertility: the importance of NO. Br J Pharmacol. 2015;172:1455-67.

49. Herrero MB, Pérez Martínez S, Viggiano JM, Polak JM, de Gimeno MF. Localization by indirect immunofluorescence of nitric oxide synthase in mouse and human spermatozoa. Reprod Fertil Dev. 1996;8:931-4.

50. Kushwaha S, Jena GB. Telmisartan ameliorates germ cell toxicity in the STZ-induced diabetic rat: studies on possible molecular mechanisms. Mutat Res. 2013;755:11-23.

51. Patel S, Santani D. Role of NF-kappa B in the pathogenesis of diabetes and its associated complications. Pharmacol Rep. 2009;61:595-603.

52. Heeba GH, Hamza AA. Rosuvastatin ameliorates diabetes-induced reproductive damage via suppression of oxidative stress, inflammatory and apoptotic pathways in male rats. Life Sci. 2015;141:13-9.

53. Funahashi H. Induction of capacitation and the acrosome reaction of boar spermatozoa by L-arginine and nitric oxide synthesis associated with the anion transport system. Reproduction. 2002;124: 857-64.

54. Hou M-L, Huang S-Y, Lai Y-K, Lee W-C. Geldanamycin augments nitric oxide production and promotes capacitation in boar spermatozoa. Anim Reprod Sci. 2008;104:56-68.

55. Aquila S, Giordano F, Guido C, Rago V, Carpino A. Insulin affects sperm capacity in pig through nitric oxide. Asian J Androl. 2013;15:835-7.

56. Corbett JA, Tilton RG, Chang K, Hasan KS, Ido Y, Wang JL, et al. Aminoguanidine, a novel inhibitor of nitric oxide formation, prevents diabetic vascular dysfunction. Diabetes. 1992;41:552-6.

57. Alizadeh R, Navid S, Abbasi N, Yari A, Mazaheri Z, Daneshi E, et al. The effect of aminoguanidine on sperm motility and mitochondrial membrane potential in varicocelized rats. Iran J Basic Med Sci. 2016;19:1279-84.

58. Lee WY, Lee R, Kim HC, Lee KH, Cui XS, Kim NH, et al. Pig spermatozoa defect in acrosome formation caused poor motion parameters and fertilization failure through artificial insemination and in vitro fertilization. Asian Australas J Anim Sci. 2014;27:1417-25.

59. Thundathil J, de Lamirande E, Gagnon C. Nitric oxide regulates the phosphorylation of the threonine-glutamine-tyrosine motif in proteins of human spermatozoa during capacitation. Biol Reprod. 2003;68:1291-8.

60. Herrero MB, de Lamirande E, Gagnon C. Nitric oxide regulates human sperm capacitation and protein-tyrosine phosphorylation in vitro. Biol Reprod. 1999;61:575-81.

61. Rahman MS, Kwon W-S, Lee J-S, Kim J, Yoon S-J, Park Y-J, et al. Sodium nitroprusside suppresses male fertility in vitro. Andrology. 2014:2:899-909.

62. Jin S-K, Yang W-X. Factors and pathways involved in capacitation: how are they regulated? Oncotarget. 2017;8:3600-27.

63. Naresh S, Atreja SK. Detection, localization and tyrosine phosphorylation status of Ser/Thr protein phosphatase $1 \gamma$ in freshly ejaculated, in vitro capacitated and cryopreserved buffalo spermatozoa. Reprod Domest Anim. 2015;50:901-9.

64. Visconti PE, Westbrook VA, Chertihin O, Demarco I, Sleight S, Diekman AB. Novel signaling pathways involved in sperm acquisition of fertilizing capacity. J Reprod Immunol. 2002;53:133-50. 
65. Martínez-Ruiz A, Cadenas S, Lamas S. Nitric oxide signaling: classical, less classical, and nonclassical mechanisms. Free Radic Biol Med. 2011;51:17-29.

66. Roy SC, Atreja SK. Tyrosine phosphorylation of a 38-kDa capacitation-associated buffalo (Bubalus bubalis) sperm protein is induced by L-arginine and regulated through a cAMP/PKAindependent pathway. Int J Androl. 2008;31:12-24.

67. de Andrade AFC, Arruda RP, Torres MA, Pieri NCG, Leite TG, Celeghini ECC, et al. Nitric oxide in frozen-thawed equine sperm: effects on motility, membrane integrity and sperm capacitation. Anim Reprod Sci. 2018;195:176-84.

68. Revelli A, Soldati G, Costamagna C, Pellerey O, Aldieri E, Massobrio M, et al. Follicular fluid proteins stimulate nitric oxide (NO) synthesis in human sperm: a possible role for NO in acrosomal reaction. J Cell Physiol. 1999;178:85-92.

69. Siddique RA, Atreja SK. Effect of spermine-NONOate on acrosome reaction and associated protein tyrosine phosphorylation in Murrah buffalo (Bubalus bubalis) spermatozoa. Anim Reprod Sci. 2012;131:81-7.

70. Kameshwari DB, Siva AB, Shivaji S. Inhibition of in vitro capacitation of hamster spermatozoa by nitric oxide synthase inhibitors. Cell Mol Biol (Noisy-le-grand). 2003;49:421-8.

71. Bevers EM, Comfurius P, Dekkers DW, Zwaal RF. Lipid translocation across the plasma membrane of mammalian cells. Biochim Biophys Acta. 1999;1439:317-30.

72. Moran JM, Madejón L, Ortega Ferrusola C, Peña FJ. Nitric oxide induces caspase activity in boar spermatozoa. Theriogenology. 2008;70:91-6.

73. Visconti PE. Understanding the molecular basis of sperm capacitation through kinase design. Proc Natl Acad Sci U S A. 2009;106: 667-8.

74. Trepakova ES, Cohen RA, Bolotina VM. Nitric oxide inhibits capacitative cation influx in human platelets by promoting sarcoplasmic/endoplasmic reticulum $\mathrm{Ca} 2+$-ATPase-dependent refilling of Ca2+ stores. Circ Res. 1999;84:201-9.

75. Ji J, Benishin CG, Pang PK. Nitric oxide selectively inhibits intracellular $\mathrm{Ca}++$ release elicited by inositol trisphosphate but not caffeine in rat vascular smooth muscle. J Pharmacol Exp Ther. 1998;285:16-21.

76. Blatter LA, Wier WG. Nitric oxide decreases $[\mathrm{Ca} 2+] \mathrm{i}$ in vascular smooth muscle by inhibition of the calcium current. Cell Calcium. 1994;15:122-31.

77. Olli KE, Li K, Galileo DS, Martin-DeLeon PA. Plasma membrane calcium ATPase 4 (PMCA4) co-ordinates calcium and nitric oxide signaling in regulating murine sperm functional activity. J Cell Physiol. 2018;233:11-22.

78. Cartwright EJ, Oceandy D, Neyses L. Physiological implications of the interaction between the plasma membrane calcium pump and nNOS. Pflugers Arch. 2009;457:665-71.

79. Misko TP, Moore WM, Kasten TP, Nickols GA, Corbett JA, Tilton $\mathrm{RG}$, et al. Selective inhibition of the inducible nitric oxide synthase by aminoguanidine. Eur J Pharmacol. 1993;233:119-25.

80. Kakizawa S. Nitric oxide-induced calcium release: activation of type 1 ryanodine receptor, a calcium release channel, through non-enzymatic post-translational modification by nitric oxide. Front Endocrinol (Lausanne). 2013;4:142.

81. Hart JD, Dulhunty AF. Nitric oxide activates or inhibits skeletal muscle ryanodine receptors depending on its concentration, membrane potential and ligand binding. J Membr Biol. 2000;173:22736.

82. Brackett BG, Bousquet D, Boice ML, Donawick WJ, Evans JF, Dressel MA. Normal development following in vitro fertilization in the cow. Biol Reprod. 1982;27:147-58.

83. Herrero MB, Gagnon C. Nitric oxide: a novel mediator of sperm function. J Androl. 2001;22:349-56.

84. Wu T-P, Huang B-M, Tsai H-C, Lui M-C, Liu M-Y. Effects of nitric oxide on human spermatozoa activity, fertilization and mouse embryonic development. Arch Androl. 2004;50:173-9.

Publisher's note Springer Nature remains neutral with regard to jurisdictional claims in published maps and institutional affiliations. 